\title{
Media Video Promosi Pada Kayukayu Restaurant Alam Sutera
}

\author{
Mulyati $^{1}$, Nadya Handayani ${ }^{2}$, Revo Jati Alamsyah ${ }^{3}$ \\ ${ }^{1}$ Program Studi Manajemen Retail, Fakultas Ekonomi dan Bisnis, Universitas Raharja \\ ${ }^{2,3}$ Teknik Informatika, Fakultas Sains dan Teknologi, Universitas Raharja \\ Email: $\underline{{ }^{1} \text { mulyati@ raharja.info }}, \underline{*^{2} \text { nadya.handayani@ raharja.info }}, \underline{{ }^{3} \text { revo.jati@ raharja.info }}$
}

\begin{abstract}
Abstrak
Sarana promosi saat ini sangtlah beragam jenisnya, diantaranya video. Melalui media video promosi, masyarakat dapat mengetahui informasi yang terdapat pada KayuKayu Restaurant. Kayukayu Restaurant merupakan tempat makan ramah keluarga dengan desain yang terkini dan unik, menyatu dengan alam yang berada di Kota Tangerang Selatan. Masalah yang dialami КауиKayu Restaurant mengalaminya penurunan jumlah pengunjung yang diakibatkan dari pandemic covid-19 serta belum mempunyai media video promosi terbaru. Tujuan melakukan penelitian ini untuk menyebarkan informasi terbaru mengenai KayuKayu Restaurant. Penelitian ini memakai 3 metode seperti pengumpulan data yaitu Observasi, Wawancara, Studi Pustaka, Menggunakan Perangkat lunak: Adobe Premiere, Photoshop, Audition dan KPM yaitu: Pra Produksi, Produksi dan Pasca Produksi. Hasil penelitian nantinya akan menjadi media video promosi pada KayuKayu Restaurant yang dapat menarik customer juga relasi untuk berkunjung atau mengadakan event di KayuKayu Restaurant.
\end{abstract}

Kata Kunci - Media Video, Restaurant, Promosi

\begin{abstract}
Currently, there are various types of promotional media, including media video. Through promotional video media, the public can find out the information contained in KayuKayu Restaurant. Kayukayu Restaurant is a family-friendly place to eat with the latest and unique designs, blending with nature that is located in Kota Tangerang Selatan. The problems experienced by KауиKayu Restaurant have decreased the number of visitors due to the covid-19 pandemic and do not yet have the latest promotional video media. The purpose of doing this research is to disseminate the latest information about KayuKayu Restaurant. This research uses 3 methods such as data collection namely Observation, Interview, Literature Study, Using Software: Adobe Premiere, Photoshop, Audition and KPM namely: Pre Production, Production and Post Production. The results of the research will later become a promotional video media for the KayuKayu Restaurant that can attract customers and relations to visit or hold events at the KayuKayu Restaurant.
\end{abstract}

Keywords - Media Video, Restaurant, Promotion

\section{PENDAHULUAN}

Video promosi yaitu "alat komunikasi yang memberikan pesan jejak positif kepada audience yang bersifat komersil [1]". Promosi "kegiatan untuk meyakinkan konsumen atas produk yang ditawarkan dengan nilai lebih ${ }^{[2],}$.

KауиКауи Restaurant merupakan tempat makan berkonsep ramah keluarga yang berkultur Indonesia serta memiliki desain terkini dan unik sehingga dapat membawa kita dengan kehidupan perkotaan yang dapat menyatu dengan alam yang menenangkan. Restaurant juga menyajikan 97 jenis menu makanan Nusantara pilihan dan berbagai jenis minuman. KayuKayu berada di Kota Tangerang Selatan. Restaurant memiliki fasilitas function room untuk berbagai macam event diantaranya: Merbau room, Merbau II room, Jati room, Ulin room dan 
Gaharu room. KayuKayu juga menyediakan fasilitas seperti Makeup room dan Smoking Area.

KayuKayu Restaurant mempunyai suatu permasalahan mengalaminya penurunan jumlah customer karena Pandemi Covid-19 dan berdampak pada pemasukan sehingga harus mengurangi beberapa karyawan serta belum mempunyai video promosi terbaru dengan info terlengkap.

Tujuan dibuatnya suatu media video promosi ini untuk menyebarkan informasi seputar KayuKayu Restaurant secara terbaru dan lengkap, sehingga dapat menarik para customer serta relasi buat datang juga mengadakan event di KayuKayu Restaurant.

\section{METODE PENELITIAN}

(1) Mengumpulkan data menggunakan Observation, Interview, literature Review. (2) Video promosi ini memakai perangkat lunak Adobe Premiere, Photoshop dan Audition. (3) Konsep Produksi Media (KPM) yaitu: PraProduksi, Produksi dan Pascaproduksi.

\section{Literature Review}

Dibawah ini terdapat refrensi tentang video promosi diantaranya:

1. Karya ilmiah dari Dewi dani Zam Zam Nurjaman (2017) "Penggunaan jejaring sosial twitter sebagai media promosi pada restoran ranjang 69" Tujuannya untuk mengetahui penggunaan jejaring sosial twitter sebagau media promosi dalam komunikasi pemasaran restoran ranjang $69 .{ }^{[2]}$

2. Artikel ilmiah yang dilakukan oleh Hadi dan Muhammadd Lathif menggunakan judul "Pembuatan iklan restoran masakan jepang tomodachi sukoharjo sebagai media informasi berbasis multimedia" penelitian ini bertujuan Untuk membuat sebuah iklan multimedia mengenai restoran sebagai media infrmasi dan promosi. ${ }^{[3]}$

3. Penelitian yang dilakukan oleh Sunarya, Lusyani. Ayunda dan Nadya (2021) "Media video promosi pada Roofpark Café \& Restaurant Puncak Bogor Jawa Barat" Untuk menghasilkan media video promosi yang terbaru guna meningkatkan jumlah pengunjung yang datang. ${ }^{[1]}$

4. Artikel ilmiah yang dibuat Fajar, Ibnu. Nasrul Kamal dan Dini Faisal (2017) "Perancangan Video Promsi Cafe OmBewok" Artikel ilmiah dibuat untuk mempengaruhii target audience agar melakukan pembelian, sehingga bisa menaikkan jumlah penjualan. ${ }^{[4]}$

5. Penelitian yang dilakukan oleh Tunjung sari dan putu eka (2017) dengan judul "Analys on promotion and the influence of social media ini restaurant industry ubud, bali, indonesia" penelitian ini bertujuan untuk menyelidiki tren pemasaran dalam mempromosikan restaurant di ubud agar meningkatnya pelanggan yang datang. ${ }^{[5]}$

6. Penelitian yang dilakukan oleh Domingo (2018) dengan judul "Product, pricing and promotional strategis of restaurants in nueva ecija: an ssessment" tujuan dari penelitian yaitu untuk menciptakan promosi yang efektif dan informatif dalam bentuk media audio visual. ${ }^{[6]}$

\section{HASIL DAN PEMBAHASAN}

\subsection{Pra Produksi}

Pra Produksi ialah kolaborasi antar pemain serta kru saat membentuk suatu visual yang disusun sesuai konsep skenario. Dibawah ini tahapan-tahapan dalam Pra Produksi yaitu.: 


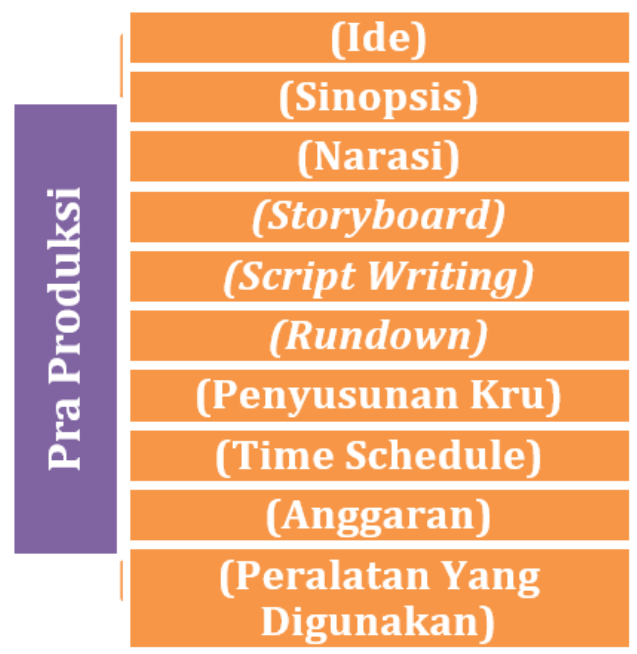

Gambar 1. Pra Produksi

1. Ide

Sebuah awalan pada tahapan Pra Produksi dalam pembuatan video promosi di KayuKayu Restaurant, mulai dari ide kemudian dikembangkan menjadi suatu konsep dengan cara observasi. Dalam video ini menampilkan visual, audio, effect visual, voice over dan music yang dikemas secara menarik dan lengkap.

2. Sinopsis

Tahapan dimana sebuah intisari cerita singkat tanpa mengurangi unsur penting dalam keseluruhan ceritanya. Berikut ialah sinopsis pada video promosi KayuKayu Restaurant:

"KayuKayu Restaurant merupakan salah satu tempat makan sekaligus vanue untuk mengadakan sebuah event, seperti birthday party, wedding, engagement, maupun event yang lainnya. KayuKayu Restaurant berada di Kota Tangerang Selatan. Memiliki konsep yang unik karena keseluruhan restaurant ini dipenuhi dengan interior kayu yang menjadi komponen utama, restaurant ini juga sebagai tempat makan ramah keluarga yang dapat menciptakan suatu kehangatan dan menyatu dengan alam karena hampir setiap sudut ruangan terdapat pepohonan serta tanam-tanaman. Tempat ini cocok untuk menghilangkan rasa kejenuhan pada kehidupan perkotaan, karena pengunjung bisa mendapatkan suasana yang tenang jika berada disini. Kayukayu restaurant memiliki fasilitas seperti makeup room, function room, smoking area dan berbagai macam menu makanan khas Nusantara dan berbagai macam jenis minuman yang tentunya tidak diragukan lagi kualitasnya."

3. Narasi

Narasi yang dirancang oleh penulis naskah dengan cara sedikit demi sedikit, yg dimulai dari ide kemudian dituangkan dalam visual. Berikut narasi yang dibuat:

"KayuKayu Restaurant yang terletak di kawasan Jalur Sutera Kota Tangerang selatan ini mempunyai desain dan konsep yang sangat menarik / KayuKayu Restaurant selalu memberikan pelayanan yang hangat kepada setiap tamu yang datang // Untuk mendapatkan suasana yang tenang tempat ini cocok banget untuk menghilangkan rasa kejenuhan kamu pada kehidupan perkotaan // KayuKayu Restaurant memiliki varian menu unggulan makanan khas nusantara serta berbagai macam minuman // KayuKayu Restaurant juga memiliki fasilitas seperti function room // Disini kamu bisa jadikan kayukayu restaurant sebagai venue untuk mengadakan event loh // seperti meeting // birthday party // wedding maupun engagement // Mau merasakan makanan cita khas 
nusantara dengan suasana yang tenang dan nyaman / yuk datang ke KayuKayu Restaurant //"

4. Storyboard

Sebuah sketsa gambar yang berisi teknik pengambilan gambar pada setiap adegan kemudian divisualisasikan.

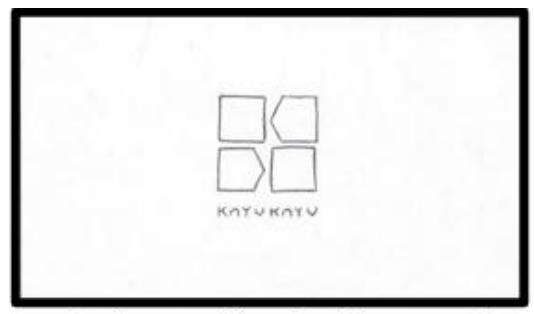

Gambar 2. Scene. 1/ video Bumper Opening logo KayuKayu Restaurant.

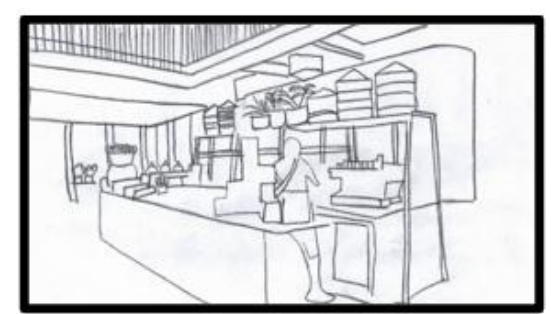

Gambar 4. Scene 3/INT/ Day/Full Shot/ Menampilkan video footage minibar.

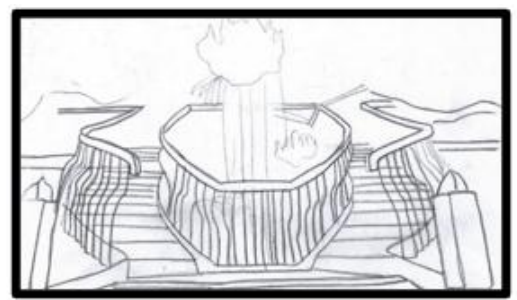

Gambar 6. Scene 5/INT/Day/Low Angle/ Menampilkan video footage tangga utama KayuKayu Restaurant.

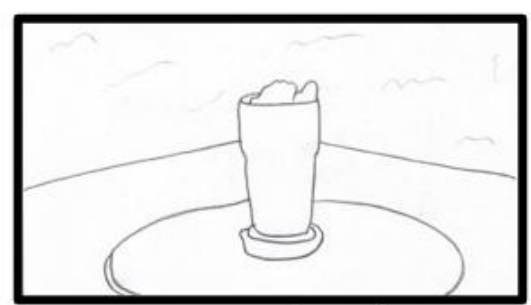

Gambar 8. Scene 7/INT/ Day/ Medium Shot/ Menampilkan video footage makanan dan minuman.

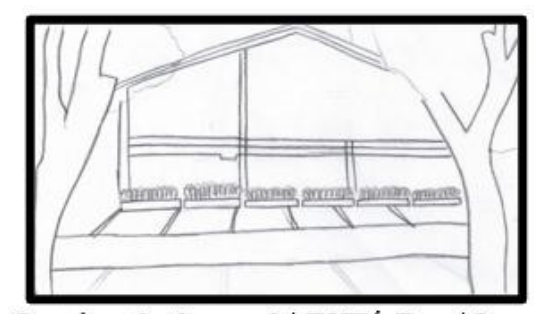

Gambar 3. Scene 2/EXT/ Day/Long Shot/Menampilkan video footage Gedung KayuKayu Restaurant.

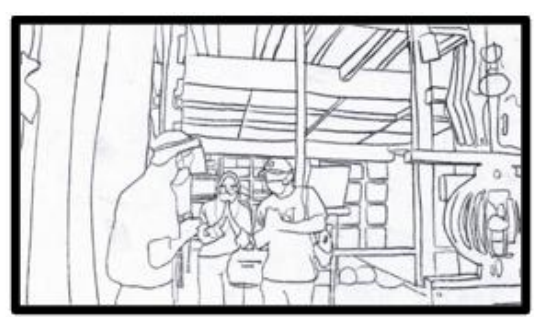

Gambar 5. Scene 4/INT/ Day/ Medium shot/Menampilkan video footage sambutan dari pegawai saat masuk.

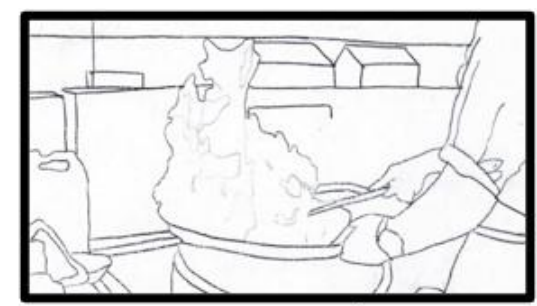

Gambar 7. Scene 6/ INT/ Day/Medium Shot/Menampilkan video footage koki masak.

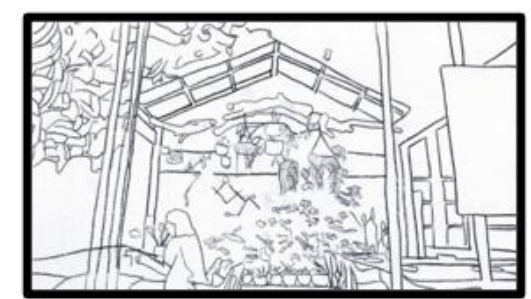

Gambar 9. Scene 8/INT/ Day/Long Shot/ Menampilkan video footage function room. 


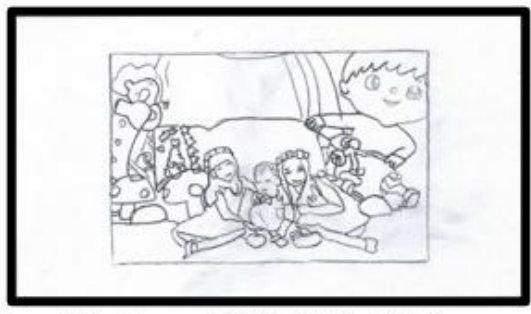

Gambar 10. Scene 9/ Full Shot/Menampilkan dokumentasi saat ada event.

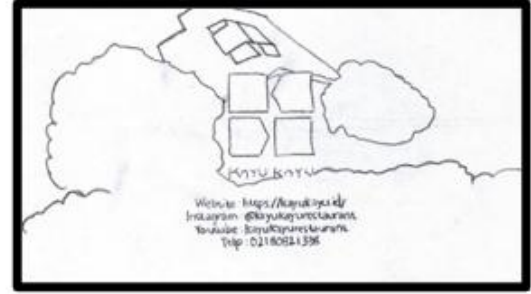

Gambar 11. Scene 10/EXT/Day/bird eye view/ Menampilkan video outro bumper logo, website, sosial media serta nomor telepon.

\section{Script Writing}

Penulisan Naskah sebuah rancangan skenario yang dibuat secara rinci, agar audience dapat membayangkan situasi dalam video tersebut. Dibawah ini terdapat Penulisan Naskah video promosi pada KayuKayu Restaurant:

Tabel 1. Script Writing

\begin{tabular}{|c|c|c|}
\hline No. & Visual & Audio \\
\hline 1. & $\begin{array}{l}\text { Video Bumper Opening logo KayuKayu } \\
\text { Restaurant }\end{array}$ & Music \\
\hline 2. & $\begin{array}{l}\text { Video footage Gedung KayuKayu } \\
\text { Restaurant }\end{array}$ & $\begin{array}{l}\text { KayuKayu Restaurantyang terletak } \\
\text { di kawasan Jalur Sutera Kota } \\
\text { Tangerang selatan ini mempunyai } \\
\text { desain dan konsep yang sangat } \\
\text { menarik/ }\end{array}$ \\
\hline 3. & Video footage minibar & Music \\
\hline 4. & $\begin{array}{l}\text { Video footage sambutan dari pegawai saat } \\
\text { masuk }\end{array}$ & $\begin{array}{l}\text { KayuKayu Restaurant selalu } \\
\text { memberikan pelayanan berstandar } \\
\text { internasional dalam kultur budaya } \\
\text { masyarakat Indonesia yang hangat } \\
\text { dan bersahabat kepada setiap tamu } \\
\text { yang datang // }\end{array}$ \\
\hline 5. & $\begin{array}{l}\text { Video footage tangga utama KayuKayu } \\
\text { Restaurant }\end{array}$ & $\begin{array}{l}\text { Untuk mendapatkan suasana yang } \\
\text { tenang tempat ini cocok banget } \\
\text { untuk menghilangkan rasa } \\
\text { kejenuhan kamu pada kehidupan } \\
\text { perkotaan // }\end{array}$ \\
\hline 6. & Video footage koki masak & Music \\
\hline 7. & Video footage makanan dan minuman & $\begin{array}{l}\text { KayuKayu Restaurant memiliki } \\
\text { varian menu unggulan makanan } \\
\text { khas nusantara serta berbagai } \\
\text { macam minuman // }\end{array}$ \\
\hline 8. & Video footage function room & $\begin{array}{l}\text { KayuKayu Restaurant juga memiliki } \\
\text { fasilitas seperti function room // }\end{array}$ \\
\hline 9. & Menampilkan dokumentasi saat ada event & $\begin{array}{l}\text { Disini kamu bisa jadikan KayuKayu } \\
\text { restaurant sebagai venue untuk } \\
\text { mengadakan event loh // seperti } \\
\text { meeting // birthday party // wedding } \\
\text { maupun engagement // }\end{array}$ \\
\hline 10. & Video outro bumper logo, website, sosial & Mau merasakan makanan cita khas \\
\hline
\end{tabular}

6. Rundown

Ialah susunan rencana yang dibatasi oleh durasi, berikut runtutan dalam pembuatan video promosi pada KayuKayu Restaurant:

Tabel 2. Rundown 


\begin{tabular}{|c|c|c|c|c|c|}
\hline No. & Scene & Location & Duration & $\begin{array}{l}\text { INT/ } \\
\text { EXT }\end{array}$ & Description \\
\hline 1. & 10 & $\begin{array}{l}\text { Outdoor KayuKayu } \\
\text { restaurant }\end{array}$ & $\begin{array}{l}00.00 .00- \\
00.00 .14\end{array}$ & $E X T$ & $\begin{array}{l}\text { Menampilkan video } \\
\text { outro bumper logo, } \\
\text { website, sosial media } \\
\text { dan nomor telepon }\end{array}$ \\
\hline 2. & 2 & $\begin{array}{l}\text { Outdoor KayuKayu } \\
\text { restaurant }\end{array}$ & $\begin{array}{l}00.00 .14- \\
00.00 .29\end{array}$ & $E X T$ & $\begin{array}{l}\text { Menampilkan video } \\
\text { footage Gedung } \\
\text { KayuKayu Restaurant }\end{array}$ \\
\hline 3. & 3 & $\begin{array}{l}\text { Indoor KayuKayu } \\
\text { restaurant }\end{array}$ & $\begin{array}{l}00.00 .29- \\
00.01 .00 \\
\end{array}$ & $I N T$ & $\begin{array}{c}\text { Menampilkan video } \\
\text { footage minibar }\end{array}$ \\
\hline 4. & 4 & $\begin{array}{l}\text { Indoor KayuKayu } \\
\text { restaurant }\end{array}$ & $\begin{array}{l}00.01 .00- \\
00.01 .21\end{array}$ & $I N T$ & $\begin{array}{l}\text { Menampilkan video } \\
\text { footage sambutan dari } \\
\text { pegawai saat masuk }\end{array}$ \\
\hline 5 . & 5 & $\begin{array}{l}\text { Indoor KayuKayu } \\
\text { restaurant }\end{array}$ & $\begin{array}{l}00.01 .21- \\
00.01 .41\end{array}$ & $I N T$ & $\begin{array}{l}\text { Menampilkan video } \\
\text { footage tangga utama } \\
\text { KayuKayu Restaurant }\end{array}$ \\
\hline 6. & 6 & Kitchen & $\begin{array}{l}00.01 .41- \\
00.02 .00\end{array}$ & $I N T$ & $\begin{array}{l}\text { Menampilkan video } \\
\text { footage koki masak }\end{array}$ \\
\hline 7. & 7 & $\begin{array}{l}\text { Indoor KayuKayu } \\
\text { restaurant }\end{array}$ & $\begin{array}{l}00.02 .00- \\
00.02 .22\end{array}$ & $I N T$ & $\begin{array}{c}\text { Menampilkan video } \\
\text { footage makanan dan } \\
\text { minuman }\end{array}$ \\
\hline 8. & 8 & Function Room & $\begin{array}{l}00.02 .22- \\
00.02 .39\end{array}$ & $I N T$ & $\begin{array}{l}\text { Menampilkan video } \\
\text { footage function room }\end{array}$ \\
\hline
\end{tabular}

7. Penyusunan Kru

Susunan Kru dalam pembuatan video promosi KayuKayu Restaurant:

Tabel 3. Susunan Kru

\begin{tabular}{|c|l|l|}
\hline No. & \multicolumn{1}{|c|}{ Jabatan } & \multicolumn{1}{c|}{ Nama } \\
\hline 1. & Sutradara & Nadya Handayani \\
\hline 2. & Cameraman & Nadya Handayani \\
\hline 3. & Asisten Cameraman & Rizky Ramadhan \\
\hline 4. & Editor & Nadya Handayani \\
\hline 5. & Script Writer & Nadya Handayani \\
\hline 6. & Dubber & Siti Rodhiah Huludjannah \\
\hline 7. & Talent & $\begin{array}{l}\text { 1. Reno Febriansyah } \\
\text { 2. Tyan Syam }\end{array}$ \\
\hline
\end{tabular}

8. Rundown

Jadwal pada saat proses produksi berlangsung disebut Rundown. Dibawah ini rundown pada video promosi KayuKayu Restaurant:

Tabel 4. Rundown 
Print ISSN: 2723-1992

Online ISSN: 2723-200X

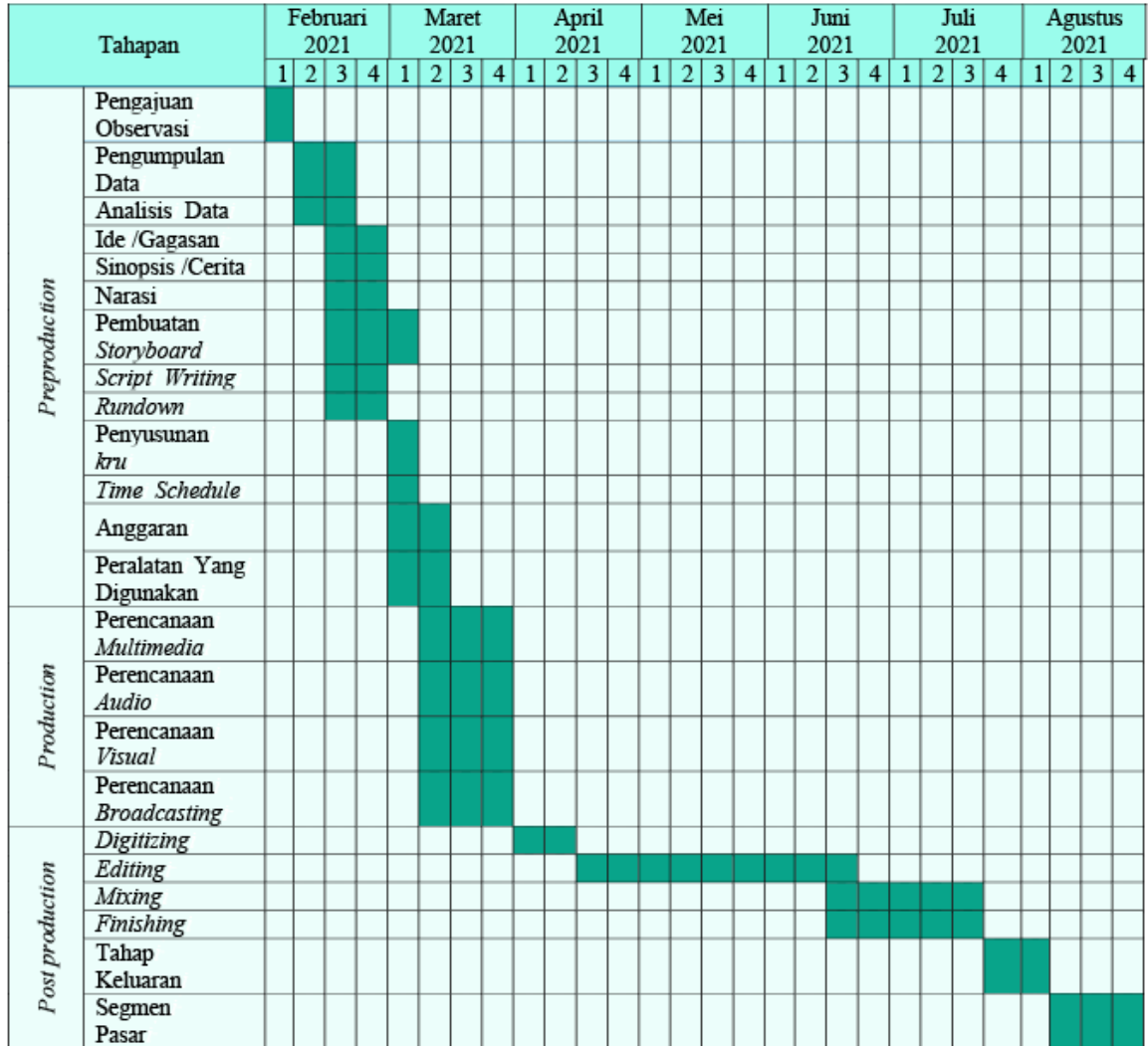

\section{Anggaran}

Anggaran yaitu pengeluaran yang dilakukan pada saat produksi. Berikut anggaran video promosi KayuKayu Restaurant:

Tabel 5. Anggaran Produksi

\begin{tabular}{|c|c|c|c|}
\hline No. & Alat Produksi & Keterangan & Biaya Produksi \\
\hline 1. & Survey Lokasi & 3 hari & $\begin{array}{c}\text { Rp. } 65.000 \times 3 \text { Hari }=\text { Rp. } \\
195.000\end{array}$ \\
\hline 2. & Kamera Sony A6000 & Sewa & @Rp. 350.000 \\
\hline 3. & Lensa sigma $35 \mathrm{~mm}$ & $\begin{array}{l}\text { Sewa (include } \\
\text { kamera) }\end{array}$ & $\begin{array}{c}\text { Rp. } 350.000 \times 2 \text { Hari }=\text { Rp. } \\
700.000 \times 2 \text { buah }=\text { Rp. } \\
1.400 .000\end{array}$ \\
\hline 4. & Lensa 7 artisan $25 \mathrm{~mm}$ & $\begin{array}{c}\text { Sewa (include } \\
\text { kamera) }\end{array}$ & - \\
\hline 5. & Lensa Sony $16 \mathrm{~mm}$ & $\begin{array}{c}\text { Sewa (include } \\
\text { kamera) }\end{array}$ & - \\
\hline 6. & Dji Mavic miniDrone & Milik Pribadi & - \\
\hline 7. & Gimbal Moza air & Milik Pribadi & - \\
\hline 8. & Tripod & Milik Pribadi & - \\
\hline 9. & Memory Lexar $32 g b$ & Milik Pribadi & - \\
\hline 10. & $D V D+$ Label + Casing & Beli & - \\
\hline 11. & Transportasi Mobil & Milik Pribadi & @Rp. 14.000 \\
\hline 12. & Bensin & Beli & Rp. $14.000 \times 4$ buah $=$ \\
\hline 13. & Voice Over & Jasa Dubber & Rp. 56.000 \\
\hline \multicolumn{3}{|c|}{ TOTAL } & Rp. 2,311,000 \\
\hline
\end{tabular}


10. Peralatan yang digunakan

Membuat video promosi KayuKayu Restaurant menggunakan peralatan seperti Kamera Sony A6000, Dji Mavic miniDrone, Lensa sigma 35mm, Lensa 7 artisan 25mm, Lensa Sony 16mm, Gimbal Moza air, Tripod, Memory Lexar 32Gb, DVD + Label + Casing, Handphone, Personal Computer.

\subsection{Produksi}

Tahapan pengambilan gambar pada waktu di lapangan berlangsung, pemain dan kru harus bekerjasama guna kelancaran tahapan produksi, di dalam produksi ada 4 tahapan yaitu:

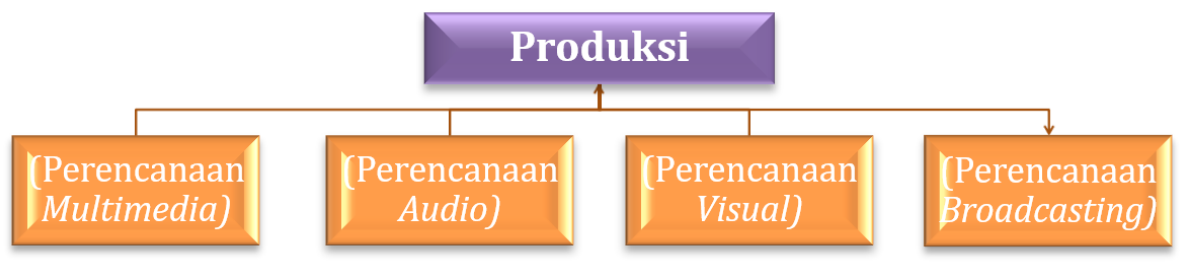

\section{Program Visual}

Gambar 12. Produksi

Dibawah terdapat tampilan isi video promosi pada KayuKayu Restaurant sebagai berikut:

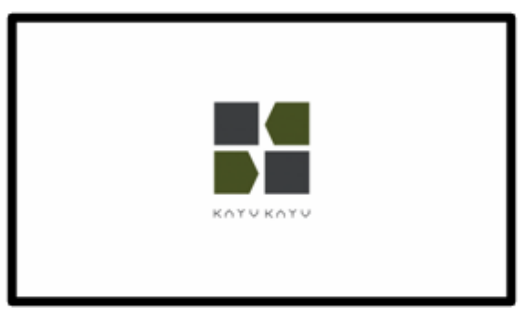

Gambar 13. Scene. 1/ video Bumper Opening logo KayuKayu Restaurant.

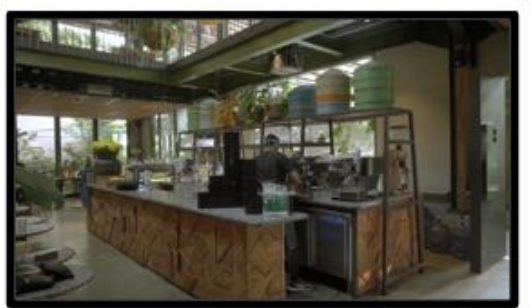

Gambar 15. Scene 3/INT/ Day/ Full Shot/Menampilkan video footage minibar.

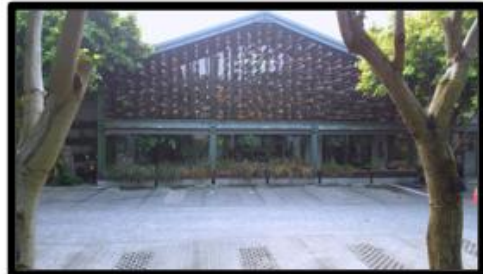

Gambar 14. Scene 2/EXT/Day/Long Shot/ Menampilkan video footage Gedung KayuKayu Restaurant.

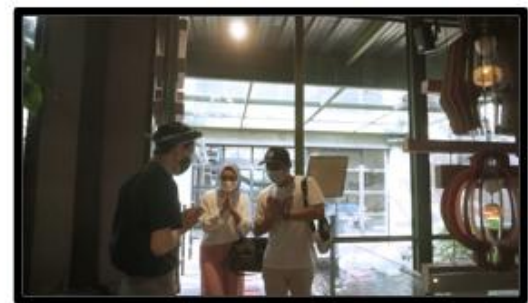

Gambar 16. Scene 4/INT/Day/ Medium shot/Menampilkan video footage sambutan dari pegawai saat masuk. 
Print ISSN: 2723-1992

Online ISSN: 2723-200X

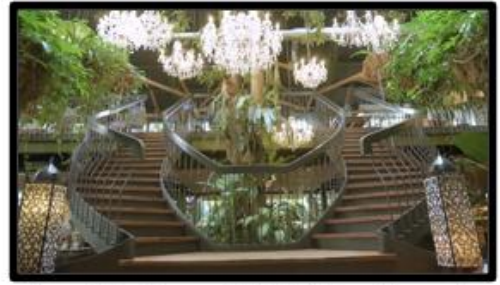

Gambar 17. Scene 5/INT/Day/Low Angle/ Menampilkan video footage tangga utama KayuKayu Restaurant.

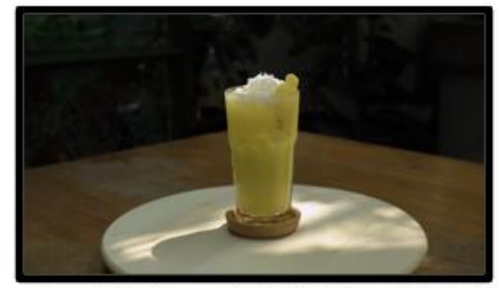

Gambar 19. Scene 7/INT/ Day/ Medium Shot/Menampilkan video footage makanan dan minuman.

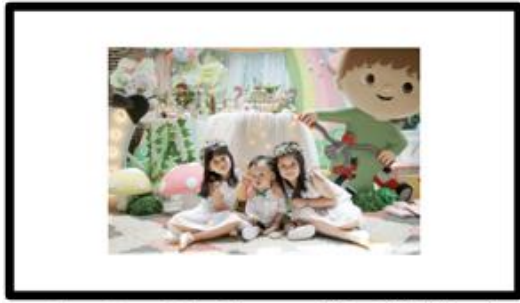

Gambar 21. Scene 9/ Full Shot/

Menampilkan dokumentasi saat ada event.

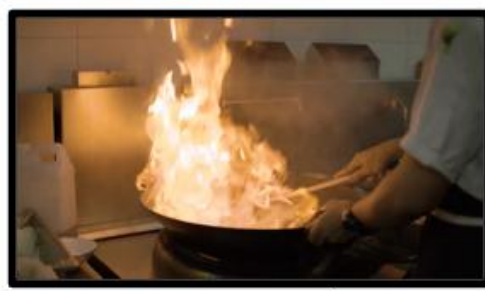

Gambar 18. Scene 6/ INT/ Day/Medium Shot/Menampilkan video footage koki masak.

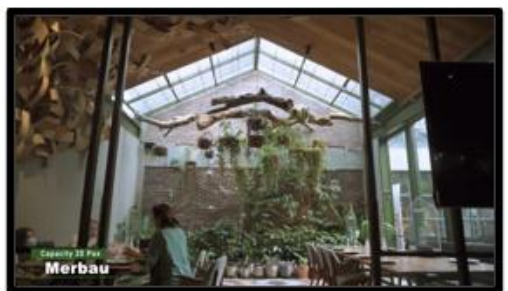

Gambar 20. Scene 8/INT/ Day/Long Shot/ Menampilkan video footage function room.

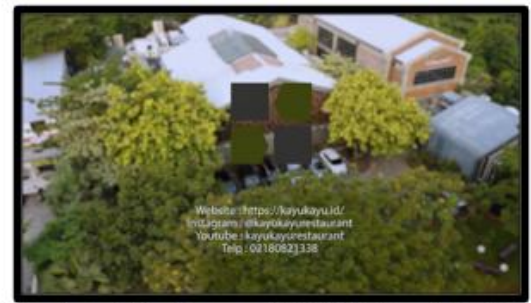

Gambar 22. Scene 10/EXT/Day/bird eye view/Menampilkan video outro bumper logo, website, sosial media serta nomor telepon.

3.3. Pasca Produksi

Pasca Produksi merupakan tahapan penyelesaian dan percampuran pada sebuah video.

Pada tahap ini terdiri dari:

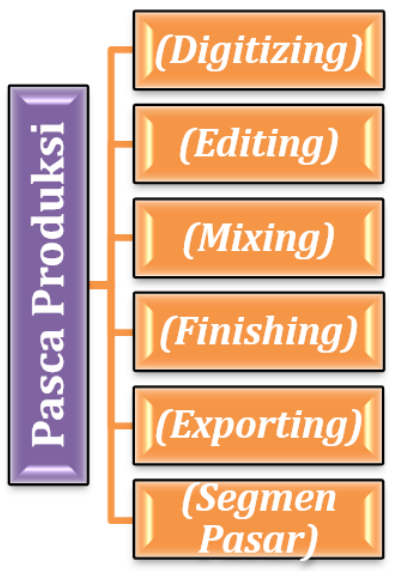

Gambar 23. Pasca Produksi

\section{Digitizing}

Tahapan pemindahan data kamera ke komputer kemudian di review supaya bisa melanjutkan proses editing, guna menghindari kerusakan, memory full atau hilang data. 


\section{Editing}

Setelah tahapan digitizing yaitu tahap pemilihan video yang ingin dimasukan kemudian proses pemotongan video setelah itu disusun menjadi sebuah video utuh dengan sesuai konsep.

\section{Mixing}

Pencampuran antara video, backsound dan dubbing agar informsi yang disampaikan jelasdan menjadi daya tarik audience.

\section{Finishing}

PadaTahap ini editor periksa kembali dengan teliti mulai dari awal sampai akhir video pada setiap adegannya serta visual effect, text, audio dan visualnya.

\section{Exporting}

Tahap akhir dalam pasca production, setelah video jadi di render kemudian di export. Kemudian di upload ke media social "@kayukayurestaurant" dan youtube kayukayurestaurant.

6. Segmen Pasar

Pada segmen pasar video promosi KayuKayu Restaurant target yang dituju daerah banten dan Jabodetabek, bahkan seluruh Indonesia (National) dan International. Sehingga dapat terjadinya peningkatan jumlah customer pada tahun berikutnya.

\section{KESIMPULAN}

Setelah melakukan observasi yang dilakukan secara langsung di KayuKayu Restaurant ternyata terdapat sebuah permasalahan yaitu mengalaminya penurunan jumlah customer yang diakibatkan oleh pandemic covid-19 yang berdampak pada pemasukan sehingga harus mengurangi beberapa karyawan serta belum mempunyai media promosi dengan informasi terbaru. Informasi yang disampaikan dalam video promosi ini terdapat fasilitas seperti function room untuk berbagai macam event diantaranya: Merbau room, Merbau II room, Jati room, Ulin room dan Gaharu room. Restaurant ini juga menyediakan fasilitas seperti Makeup room dan Smoking Area. KayuKayu Restaurant juga memiliki varian menu makanan khas nusantara dan berbagai macam minuman, serta lokasi dan identitas KayuKayu Restaurant. Video promosi ini akan di implementasikan pada sosial media “@kayukayurestaurant dan youtbe KayuKayu Restaurant dengan informasi yang lengkap, jelas dan terbaru, tentunya tidak lupa menggunakan visual effect agar dapat menarik minat audience.

\section{SARAN}

Hasil penelitian ini terdapat beberapa saran untuk KayuKayu Restaurant yaitu: Agar tetap terus menyajikan informasi terbaru dan terus menaikkan pemasaran kepada pengunjung. Dengan adanya video ini mahasiswa menyarankan untuk terus melakukan pengembangan kegiatan promosi ini, setidaknya setahun sekali dengan konsep yang lebih trendy. Agar dapat memperluas kegiatan promosi disarankan untuk menyajikan video yang dikemas secara menarik agar pengunjung dapat tertarik untuk berkunjung maupun mengadakan event di KayuKayu Restaurant.

\section{DAFTAR PUSTAKA}

[1] Sunarya, Lusyani, Ayunda Dwi Purbayani dan Nadya Handayani, 2021, "Media Video Promosi Pada Roofpark Café \& Restauranti Puncak Bogor Jawa Barat". Tangerang: Universitas Raharja. TMJ Journal. P-ISSN: 2620-3383 Vol 5, No 2. 
[2] Dewi, Rosanti Utami dan Zam Zam Nurjaman. 2017. "Penggunaan Jejaring Sosial Twitter Sebagai Media Promosi Pada Restoran Ranjang 69”, Jawa Barat: Universitas Garut, "Jurnal Komunikasi dan Media, ISSN: 2527-8673, Vol 1, No 2.

[3] Hadi, Widiyanto dan Muhammad Lathif (2017). "Pembuatan Iklan Restoran Masakan Jepang "Tomodachi” Sukoharjo Sebagai Media Informasi Berbasis Multimedia”. Surakarta: AMIK Cipta Darma Surakarta. Jurnal IT CIDA. ISSN: 2477-8133. Vol. 3, No. 2.

[4] Fajar, Ibnu, Nasrul Kamal dan Dini Faisal, 2017, "Perancangan Video Promosi Café OmBewok", Padang: Universitas Negeri Padang. Jurnal DEKAVE. ISSN: 23023228. Vol 5,

[5] Tunjungsari, Komang Ratih dan Putu Eka Wirawan, 2017, "Analysis on Promotion and the Influence ofiocial Media in Restaurant Industry, Ubud, Bali, Indonesia”. Bali: Sekolah Tinggi Pariwisata Bali Internasional (STPBI). International Journal of Research in Social Sciences, ISSN: 2249-2496, Vol 7, No 5.

[6] Domingo, A. V, 2018, "Product, pricing and promotional strategies of Restaurants in Nueva Ecija: An Assessment", Philippines: Nueva Ecija University of Science and Technology, International Journal of Advancedi Engineering, Managementand Science (IJAEMS), ISSN: 2454-1311, Vol 4, No 11. 